\title{
PENGARUH KOMITMEN TERHADAP KINERJA KARYAWAN PADA PT. BANK PANIN Tbk CABANG PEMATANGSIANTAR
}

\author{
Oleh: \\ Denny Indayang \\ S1 Manajemen \\ Darwin Lie, Marisi Butarbutar, Efendi
}

\begin{abstract}
Abstraksi
Adapun yang menjadi rumusan masalah dalam penelitian ini adalah bagaimana pengaruh komitmen terhadap kinerja karyawan pada PT. Bank Panin Tbk Cabang Pematangsiantar. Data-data yang dikumpulkan berupa data kualitatif dan data kuantitatif. Untuk teknik analisa yang digunakan adalah teknik analisis deskriptif kualitatif dan analisis deskriptif kuantitatif .

Dari hasil analisis regresi sederhana didapatkan $\hat{\mathrm{Y}}=23,6968+0,69466 \mathrm{X}$, yang artinya ada pengaruh positif antara komitmen terhadap kinerja. Nilai koefisien korelasi didapat sebesar 0,49099 yang artinya ada hubungan sedang dan positif antara komitmen dan kinerja. Koefisien determinasi yang didapatkan adalah $24,11 \%$ yang artinya tinggi rendahnya kinerja dijelaskan oleh komitmen sebesar $24,11 \%$ dan sisanya sebesar $75,89 \%$ dipengaruhi faktor lain yang tidak dibahas seperti motivasi, kepemimpinan, lingkungan kerja, perencanaan karir, dan pendelegasian wewenang. Dari perhitungan uji $\mathrm{t}_{\text {hitung }}$ diperoleh 3,609 dan $\mathrm{t}_{\text {tabel }} 2,020$ di mana $\mathrm{t}_{\text {hit }}>\mathrm{t}_{\text {tab }}$ yang menunjukkan bahwa $\mathrm{H}_{0}$ ditolak dan menunjukkan adanya pengaruh positif antara komitmen terhadap kinerja. Dari hasil evaluasi diketahui bahwa pimpinan harus memperhatikan rasa kebersamaan dan saling memiliki di antara karyawan. Dan untuk meningkatkan kinerja pimpinan perusahaan harus melaksanakan pengembangan karyawan dengan melakukan training secara berkala.
\end{abstract}

Kata kunci: Komitmen dan Kinerja

Abstraction

As for becoming internal issue formula this research is how influence commitment to employees performance PT. Bank Panin Tbk Branch the Pematangsiantar. Data collected by in the form of data qualitative and quantitative data. For the technique of analysis used by descriptive analysis technique qualitative and descriptive analysis is quantitative.

Than result analyze the regretion is $\hat{\mathrm{Y}}=23,6968+0,69466 X$, what its meaning there is positive influence between commitment to performance. Assess the correlation coefficient got by equal to 0,49099 which its meaning there relation and positive between commitment and performance. Coefficient Determination got is $24,11 \%$ what its meaning is high lower the performance explained by commitment equal to $24,11 \%$ and the rest of equal to 75,89\% influenced by the of the factor which is not studied like motivation, leadership, environmental work the, career planning, and authority delegation. From calculation test the $t_{\text {hit }}$ obtained by 3,609 and $t_{\text {tab }} 2,020$ where about $t_{\text {hit }}>t_{\text {tab }}$ indicating that $H_{0}$ refused and show the existence of positive influence between commitment to performance. From result evaluate known that by the head have to pay attention to feel the togetherness and [is] owning each other among employees. And to increase performance of company head have to execute the employees development by conducting periodical training.

Keyword: Commitment And Performance

\section{A. PEndahuluan}

\section{Latar Belakang Masalah}

PT. Bank Panin Tbk Cabang Pematangsiantar sebagai perusahaan yang bergerak di bidang perbankan memandang kinerja sebagai dimensi utama dalam pencapaian tujuan. Tentunya kinerja dalam PT. Bank Panin Tbk Cabang Pematangsiantar bukannya tanpa masalah. Adapun fenomena yang dihadapi adalah belum cukup optimalnya kinerja karyawan yang ada. Dari sisi penilaian kinerja oleh PT. Bank Panin Tbk Cabang Pematangsiantar terhadap karyawannya, kuantitas yang dapat dihasilkan sudah memadai, begitu juga dari segi kualitas, ketepatan, jumlah kehadiran, dan kemampuan bekerja sama. Namun hal yang menjadi kendala adalah ketidaktelitian, keterlambatan dan ketidakhadiran dari karyawan. Walapun tidak begitu signifikan, ketidaktelitian menyebabkan kesalahan penulisan slip transaksi, bahkan salah penginputan data. Dari segi keterlambatan dan ketidakhadiran, masih ada beberapa karyawan masih ada yang tidak taat pada jam kehadiran dan tidak hadir bekerja selama beberapa hari.

Kendala-kendala di atas tidak terlepas dari komitmen karyawan itu sendiri. Komitmen yang ada di PT. Bank Panin Tbk Cabang Pematangsiantar 
terdiri dari affective commitment, continuance commitment, dan normative commitment. Dari segi affective commitment, karyawan ikut andil dalam pengembangan perusahaan dan merasa bangga menjadi bagian perusahaan. Dari segi continuance commitment, karyawan merasa rugi apabila meninggalkan perusahaan dan tidak merasa tertarik pada tawaran perusahaan lain. Sedangkan dari segi normative commitment, karyawan menganggap bahwa loyalitas terhadap perusahaan sangat penting dan setia pada perusahaan. Tentunya tingkat komitmen karyawan yang rendah dapat menyebabkan meningkatnya jumlah absensi, penurunan kinerja, dan sebagainya, dan terutama menyebabkan karyawan tidak melakukan pekerjaannya lebih baik dan tidak memiliki kewajiban dalam turut serta memajukan perusahaan.

\section{Rumusan Masalah}

Berdasarkan uraian dari latar belakang di atas, maka rumusan masalah penelitian ini adalah: bagaimana pengaruh komitmen terhadap kinerja karyawan pada PT. Bank Panin Tbk Cabang Pematangsiantar?

\section{Tujuan Penelitian}

Adapun tujuan penelitian yang dilakukan adalah sebagai berikut: untuk mengetahui pengaruh promosi terhadap Loyalitas Konsumen pada PT. Alam Terang Mandiri cabang pematangsiantar.

\section{Metode Penelitian}

Desain penelitian merupakan suatu cara yang sistematis dan objektif dengan maksud untuk memperoleh data atau mengumpulkan keterangan untuk diteliti. Adapun Desain penelitian yang digunakan adalah Penelitian Kepustakaan (Library Research) dan Penelitian Lapangan (Field Research).

Teknik pengumpulan data yang dilakukan penulis dalam penelitian ini adalah berupa Kuesioner, Wawancara dan Dokumentasi. Tehnik analisa data yang digunakan dalam penelitian ini antara lain Tehnik Analisa Deskriptif Kualitatif dan Tehnik Analisa Deskriptif Kuantitatif.

\section{B. LANDASAN TEORI}

\section{Komitmen}

Menurut Mathis dan John (2006:122), komitmen organisasional adalah tingkat sampai mana karyawan yakin dan menerima tujuan organisasional, serta berkeinginan untuk tinggal bersama organisasi tersebut. Sedangkan menurut Porter dalam Panggabean (2004:135), komitmen adalah kuatnya pengenalan dan keterlibatan seseorang dalam suatu organisasi tertentu.

Meyer dan Allen dalam Luthans (2006:249) mengemukakan bahwa ada tiga komponen organisasional, yaitu: Affective Commitment (Komitmen Afektif), Continuance Commitment (Komitmen Kelanjutan), Normative Commitment (Komitmen Normatif). Kanter dalam Sopiah
(2008:158) mengemukakan adanya tiga bentuk komitmen organisasional, yaitu:

a) Komitmen berkesinambungan (continuance commitment), yaitu komitmen yang berhubungan dengan dedikasi anggota dalam melansungkan kehidupan organisasi dan menghasilkan orang yang mau berkorban dan berinvestasi pada organisasi.

b) Komitmen terpadu (cohesion commitment), yaitu komitmen anggota terhadap organisasi sebagai akibat adanya hubungan social dengan anggota lain di dalam organisasi. Ini terjadi karena karyawan percaya bahwa norma-norma yang dianut organisasi merupakan norma-norma yang bermanfaat.

c) Komitmen terkontrol (control commitment), yaitu komitmen anggota pada norma organisasi yang memberikan perilaku ke arah yang diinginkanmya. Norma-norma yang dimiliki organisasi sesuai dan mampu memberikan sumbangan terhadap perilaku yang diinginkannya.

David dalam Sopiah (2008:163) mengemukakan ada empat faktor yang mempengaruhi komitmen karyawan pada organisasi, yaitu: Faktor personal, Karakteristik pekerjaan, Karakteristik struktur, misalnya besar/kecilnya organisasi dan Pengalaman kerja. Komitmen karyawan terhadap organisasi adalah bertingkat, dari tingkatan yang sangat rendah hingga tingkatan yang sangat tinggi.

Ditinjau dari segi organisasi, Koch dalam Sopiah (2008:166) mengemukakan bahwa karyawan yang berkomitmen rendah akan berdampak pada perputaran (turn over). Dampak lain adalah tingginya ketidakhadiran, meningkatnya kelambanan kerja dan kurangnya intensitas untuk bertahan sebagai karyawan di organisasi tersebut sebagaimana seperti yang dikemukakan oleh Angle dalam Sopiah (2008:166).

\section{Kinerja}

Kinerja dalam bahasa Indonesia dengan kata dasar "kerja" di mana kinerja juga sering disebut sebagai hasil kerja. Menurut Mathis dan John (2006:378), kinerja (performance) pada dasarnya adalah apa yang dilakukan atau tidak dilakukan oleh karyawan. Menurut Hasibuan (2008:94), kinerja adalah suatu hasil kerja yang dicapai seseorang dalam melaksanakan tugas-tugas yang dibebankan kepadanya yang didasarkan atas kecakapan, pengalaman, dan kesungguhan serta waktu.

Mathis dan John (2006:378) mengemukakan bahwa indikator-indikator yang berhubungan dengan kinerja adalah sebagai berikut:

a) Kuantitas dari hasil: sebagai hasil dari jumlah pekerjaan yang dihasilkan oleh karyawan. Kuantitas dapat dikukur dengan rupiah, unit, dan lain-lain.

b) Kualitas dari hasil: sebagai kesempurnaan hasil pekerjaan yang dihasilkan oleh karyawan. 
c) Ketepatan waktu dari hasil: sebagai kesesuaian penyelesaian pekerjaan karyawan dengan tenggat waktu yang disediakan.

d) Kehadiran: yaitu ketepatan dari para karyawan untuk hadir di tempat kerja sesuai atau lebih awal dari waktu yang ditentukan.

e) Kemampuan bekerja sama: Yaitu kesediaan dari karyawan untuk bekerja sama dalam satu tim dalam menyelesaikan pekerjaan.

Menurut Dharma dalam Nugroho (2009:5), indikator-indikator kinerja adalah antara lain: Kuantitas kerja, Kualitas kerja, Ketepatan waktu.

Menurut Mondy (2008:257), penilaian kinerja (performance appraisal) adalah sistem formal untuk menilai dan mengevaluasi kinerja tugas individu atau tim. Bagi banyak organisasi, tujuan utama sistem penilaian adalah untuk memperbaiki kinerja individual dan organisasi.

\section{PEMBAHASAN}

\section{Analisa}

a. Deskripsi Responden

Berikut adalah tabel-tabel yang dibutuhkan untuk mengetahui berbagai kriteria keadaan umum para pelanggan yang akan dijadikan sebagai responden.

Tabel 1

Jenis Kelamin Respoden

\begin{tabular}{|c|l|c|c|}
\hline No. & \multicolumn{1}{|c|}{$\begin{array}{c}\text { Jenis } \\
\text { Kelamin }\end{array}$} & $\begin{array}{c}\text { Frekuensi } \\
(\mathbf{f})\end{array}$ & $\begin{array}{c}\text { Persentase } \\
(\boldsymbol{\%})\end{array}$ \\
\hline 1 & Pria & 19 & $44,19 \%$ \\
\hline 2 & Wanita & 24 & $55,81 \%$ \\
\hline & Jumlah & 43 & $100 \%$ \\
\hline
\end{tabular}

Sumber: Hasil pengolahan dari data primer

Dari tabel di atas dapat dilihat responden yang mengisi kuesioner sebanyak 43 orang responden, berjenis kelamin pria sebanyak 19 orang $(44,19 \%)$ dan berjenis kelamin wanita 24 orang $(55,81 \%)$. Jumlah wanita lebih banyak dibandingkan pria karena umumnya karyawan frontliner (Teller dan Customer Service) adalah wanita.

\section{b. Analisa Deskriptif Kualitatif}

Analisis deskriptif digunakan untuk memperoleh gambaran atau deskripsi mengenai tanggapan dari karyawan mengenai Pengaruh Komitmen terhadap Kinerja Karyawan PT. Bank Panin Tbk Cabang Pematangsiantar. Sesudah melakukan pengujian data, maka untuk selanjutnya penulis akan melakukan pengkajian analisis kualitatif sebagai gambaran fenomena dari variabel penelitian pada saat sekarang ini.

Adapun penetapan kriteria nilai rata-rata jawaban dari responden tersebut dimasukkan ke dalam kelas-kelas interval dimana penentuan intervalnya memakai rumus sebagai berikut:

Interval Kelas $=\underline{\text { Nilai Tertinggi }- \text { Nilai Terendah }}$
Kriteria:

Nilai tertinggi $=5$

Nilai terendah $=1$

Jumlah kelas $=5$

Dari rumus di atas diperoleh interval kelas $=$ 0,8 , sehingga berlaku ketentuan kategori dengan hasil sebagai berikut:

Tabel 2

Nilai Interval dan Kategori Jawaban Responden.

\begin{tabular}{|c|c|}
\hline $\begin{array}{c}\text { Nilai } \\
\text { Interval }\end{array}$ & Kategori \\
\hline $1,00-1,80$ & $\begin{array}{c}\text { Sangat Tidak Baik/Sangat } \\
\text { Rendah }\end{array}$ \\
\hline $1,81-2,60$ & Tidak Baik/Rendah \\
\hline $2,61-3,40$ & Kurang Baik/Cukup Tinggi \\
\hline $3,41-4,20$ & Baik/Tinggi \\
\hline $4,21-5,00$ & Sangat Baik/sangat Tinggi \\
\hline
\end{tabular}

Sumber: Hasil Pengolahan Data.

1) Gambaran Komitmen pada PT. Bank Panin Tbk Cabang Pematangsiantar

Dari pengolahan data kuesioner sebagian besar responden menjawab tinggi pada indikator komitmen yang ada pada PT. Bank Panin Tbk Cabang Pematangsiantar. Di sini dapat terlihat peranan komitmen pada kinerja perusahaan. Apabila semakin tinggi komitmen yang dimiliki karyawan maka semakin tinggi pula kinerja perusahaan.

Secara keseluruhan, indikator komitmen memiliki nilai rata-rata 3,83 yang dinilai Tinggi. Hal ini berarti berdasarkan hasil kuesioner, karyawan PT. Bank Panin Tbk Cabang Pematangsiantar telah memiliki komitmen yang tinggi. Dengan tingginya komitmen, maka diharapkan bahwa kinerja karyawan tinggi juga.

\section{2) Gambaran Kinerja pada PT. Bank Panin Tbk Cabang Pematangsiantar}

Kinerja adalah hasil yang dicapai oleh pegawai dalam pekerjaan yang dibebankan kepadanya dalam suatu organisasi. Dari pengolhan data kuesioner dapat dilihat bahwa sebagian besar responden menjawab setuju, baik dari segi kuantitas dari hasil, kualitas dari hasil, ketepatan waktu dari hasil kehadiran dan kemampan bekerjasama. Hampir semua indikator memiliki nilai rata-rata Tinggi, dan ada dua indikator yang nilai rata-ratanya Cukup Tinggi. Dalam hal ini tentunya pimpinan harus memperhatikan indikator tersebut dan berupaya meningkatkan kinerja karyawan.

Secara keseluruhan sisi kinerja memiliki nilai rata-rata 3,71 yang dinilai Tinggi. Hal tersebut berarti berdasarkan hasil kuesioner, karyawan PT. Bank Panin Tbk Cabang Pematangsiantar telah menunjukkan kinerja yang tinggi. Hal tersebut hendaknya ditingkatkan agar kinerja pada masamasa yang akan datang bisa meningkat juga. 


\section{c. Analisa Deskriptif Kuantitatif}

\section{Regresi Linier Sederhana}

Fungsi dari analisis regresi adalah untuk melihat pengaruh yang terjadi di antara kedua variabel. Selain itu analisis regresi juga berfungsi sebagai penunjuk arah hubungan yang terjadi antara variabel dependen dan variabel indenpenden. Dalam penelitian ini, yang dibahasa adalah pengaruh komitmen terhadap kinerja karyawan. Komitmen sebagai variabel independen (bebas) dan kinerja sebagai variabel dependen (terikat). Untuk memperoleh nilai a dan $\mathrm{b}$, digunakan notasi sebagai berikut: $=\mathrm{a}+\mathrm{bX}$. Dan dari hasil perhitungan diperoleh Hasil dari koefisien regresi yang didapat adalah sebagai berikut: $\hat{\mathbf{Y}}=\mathbf{2 3 , 6 9 6 8}+\mathbf{0 , 6 9 4 6 6} \mathrm{X}$. artinya terdapat pengaruh yang positif antara komitmen (X) terhadap kinerja (Y) karyawan pada PT. Bank Panin Tbk Cabang Pematangsiantar.

\section{Korelasi dan Koefisien Determinasi}

Untuk menghitung kekuatan hubungan komitmen terhadap kinerja karyawan, dilakukan melalui analisa korelasi dengan rumus sebagai berikut:

$\mathrm{r}=\frac{n \sum X Y-\sum X \sum Y}{\sqrt{n \sum X^{2}-\left(\sum X\right)^{2}} \sqrt{n \sum Y^{2}-\left(\sum Y\right)^{2}}}$

\section{$\mathbf{r}=\mathbf{0 , 4 9 0 9 9}$}

Dari hasil perhitungan diatas, didapat nilai $r=$ 0,49099 yang artinya terdapat hubungan yang sedang dan positip antara variabel $\mathrm{X}$ yaitu komitmen dengan variabel $Y$ yaitu kinerja karyawan. Selanjutnya, untuk mengukur seberapa besar variabel bebas menjelaskan variabel terikat maka digunakan koefisien determinasi (KD). Nilai KD dapat diperoleh dari:

$$
\begin{aligned}
& \mathrm{KD}=\mathrm{r}^{2} \times 100 \% \\
& \mathrm{KD}=\mathbf{2 4 , 1 1 \%}
\end{aligned}
$$

Angka ini menunjukkan tinggi rendahnya kinerja dapat dijelaskan oleh kontribusi komitmen sebesar $24,11 \%$. Sedangkan 75,89\% dijelaskan oleh faktor-faktor lain yang tidak dibahas pada penelitian ini sepeti motivasi, kepemimpinan, lingkungan kerja, perencanaan karir, dan pendelegasian wewenang.

\section{Uji Hipotesis (uji t)}

Untuk menarik kesimpulan yang valid, maka harus dilakukan uji hipotesis. Dari hasil perhitungan koefisien korelasi diketahui bahwa komitmen berhubungan terhadap kinerja. Untuk menguji kebenarannya, dilakukan uji hipotesis. Dengan rumusan sebagai berikut:

a. $\mathrm{H} 0=0$, artinya komitmen tidak memiliki pengaruh positif terhadap kinerja karyawan pada PT. Bank Panin Tbk Cabang Pematangsiantar.

b. Ha $\neq 0$, artinya komitmen memiliki pengaruh positif terhadap kinerja karyawan pada PT. Bank Panin Tbk Cabang Pematangsiantar.

Dengan kriteria pengujian yaitu: jika $t_{\text {hit }}<t_{\text {tab }}$ atau probabilitas signifikansi $<\alpha(5 \%)$, maka Ho diterima dan $\mathrm{Ha}$ ditolak. Jika $\mathrm{t}_{\text {hit }}>\mathrm{t}_{\mathrm{tab}}$ atau probabilitas signifikansi $>\alpha(5 \%)$, maka Ho ditolak dan Ha diterima. Dengan $\alpha=0,05$ di mana $n=43$, maka nilai $\mathrm{t}$ hitung dapat dicari sebagai berikut:

$$
\mathrm{t}=\frac{\mathrm{r} \sqrt{\mathrm{n}-2}}{\sqrt{1-\mathrm{r}^{2}}}
$$

Dari hasil perhitungan uji t diperoleh nilai thit $(3,609)>$ ttab $(2,020)$ sehingga H0 ditolak. Hasil tersebut menunjukkan bahwa komitmen memiliki pengaruh positif terhadap kinerja karyawan pada PT. Bank Panin Tbk Cabang Pematangsiantar.

\section{Evaluasi}

\section{a. Komitmen}

Untuk meningkatkan nilai-nilai indicator dari komitmen yang masih dibawah nilai rata-rata, maka pimpinan harus meningkatkan komitmen karyawan sehingga karyawan enggan meninggalkan perusahaan. Beberapa hal yang dapat dilakukan adalah sebagai berikut:

1) Tingkatkan pengadaan acara-acara yang melibatkan semua anggota organisasi sehingga kebersamaan dan rasa memiliki bisa terjalin. Hal-hal yang dapat dilakukan seperti acara donor darah, bakti sosial, menanam pohon, olahraga bersama, dan lain-lain.

2) Memperhatikan perkembangan karier karyawan dalam jangka panjang dan memberlakukan karyawan secara adil dan benar. Karyawan yang telah berprestasi umumnya enggan meninggalkan perusahaan. Apabila prestasi tersebut ditunjang dengan perlakuan yang baik, karyawan akan merasa wajib untuk tinggal di perusahaan.

3) Menciptakan kondisi bekerja yang tidak monoton karena rutinitas yang sama setiap hari akan menimbulkan perasaan bosan bagi karyawan. Hal tersebut dapat dilakukan dengan melakukan rotasi pekerjaan dalam kurun waktu tertentu dan memperbaharui fasilitas-fasilitas kantor dalam jangka waktu tertentu .

4) Mengkomunikasikan tujuan perusahaan dengan para karyawan dan meminta karyawan untuk memberikan feedback. Komunikasi yang dilakukan harus dua arah sehingga pimpinan tahu apa yang dibutuhkan karyawan dan juga sebaliknya.

Ketika hal-hal di atas dilakukan dengan baik, karyawan akan merasa puas dengan perusahaan. Rasa puas tersebut akan meningkatkan komitmen dalam diri karyawan sehingga mereka tidak ingin meninggalkan peusahaan. Lebih penting lagi, kinerja karyawan dan tanggung jawab atas pekerjaan mereka dapat terlaksana dengan baik.

\section{b. Kinerja Karyawan}

Untuk indikator kinerja yang menjadi perhatian agar ditingkatkan, perlu dilakukan:

1) Memberikan pekerjaan dengan kuantitas yang meningkat dari waktu ke waktu dan memberikan pekerjaan ekstra. Hal tersebut guna melatih karyawan agar tidak kewalahan dalam 
menyelesaikan kuantitas kerja yang sewaktuwaktu bisa bertambah.

2) Memberikan pengembangan karyawan secara berkala. Pengembangan karyawan seperti training ataupun seminar diharapkan mampu meningkatkan kinerja karyawan.

3) Menetapkan peraturan yang lebih tegas dalam hal keterlambatan dan ketidakhadiran, dengan pemberian sanksi (bisa berupa pemotongan cuti atau gaji) kepada karyawan yang sering terlambat dan tidak hadir.

Karyawan sebagai sumber daya manusia merupakan aset yang penting bagi perusahaan. Kunci untuk memajukan perusahaan berada pada karyawan. Untuk meningkatkan kinerja, salah satu langkah yang dapat dilakukan perusahaan adalah meningkatkan komitmen karyawan. Semakin tinggi komitmen yang ada pada karyawan, semakin tinggi pula kontribusi yang dapat diberikan karyawan terhadap perusahaan dalam pencapaian tujuannya.

\section{KESIMPULAN DAN SARAN}

\section{Kesimpulan}

a. Berdasarkan penelitian, komitmen yang ada pada PT. Bank Panin Tbk Cabang Pematangsiantar dinilai Tinggi dengan nilai rata-rata 3,83 . Selain itu, kinerja yang ada juga dinilai Tinggi dengan nilai rata-rata 3,71. Semakin tinggi komitmen maka semakin tinggi juga kinerja.

b. Perhitungan regresi sederhana yang dilakukan didapatkan hasil $\hat{Y}=23,6968+0,69466$ X. Hal ini menunjukkan bahwa terdapat pengaruh yang positif antara komitmen (X) terhadap kinerja (Y) karyawan pada PT. Bank Panin Tbk Cabang Pematangsiantar.

c. Kekuatan hubungan melalui koefisien korelasi diketahui terdapat hubungan yang sedang dan positif antara komitmen terhadap kinerja sebesar 0,49099. Koefisien determinasi sebesar 24,11\% tinggi rendahnya kinerja pada PT. Bank Panin Tbk cabang Pematangsiantar dapat dijelaskan oleh komitmen, sedangkan sisanya $75,89 \%$ djelaskan oleh faktor-faktor lain.

d. Uji t dengan taraf signifikansi 5\% disimpulkan bahwa thitung > ttabel yaitu 3,609>2,020 maka $\mathrm{H} 0$ ditolak dan Ha diterima. Hasil uji t tersebut menunjukkan bahwa komitmen memiliki pengaruh positif terhadap kinerja karyawan pada PT. Bank Panin Tbk Cabang Pematangsiantar.

\section{Saran}

a. Tingkatkan pengadaan acara-acara yang melibatkan semua anggota organisasi sehingga kebersamaan dan rasa memiliki bisa terjalin, memperhatikan perkembangan karier karyawan dalam jangka panjang dan memberlakukan karyawan secara adil dan benar.

b. Menciptakan kondisi kerja yang tidak monoton, mengkomunikasikan tujuan perusahaan dengan para karyawan dan meminta karyawan untuk memberikan feedback. c. Memberikan pekerjaan dengan kuantitas yang meningkat dari waktu ke waktu dan memberikan pekerjaan ekstra, memberikan pengembangan karyawan secara berkala, dan menetapkan peraturan yang lebih tegas dalam hal keterlambatan dan ketidakhadiran dengan adanya sanksi yang tegas.

\section{E. DAFTAR PUSTAKA}

Dessler, Gary. 2006. Manajemen Sumber Daya Manusia Edisi Kesepuluh Jilid I. Jakarta: Penerbit Indeks.

Djajendra,

2011 , http://kecerdasanmotivasi.wordpress.com/2 011/01/05/kerja-tanpa-absen/: tahun akses 2013.

Hasibuan, H. Malayu. 2008. Organisasi dan Motivasi. Jakarta: Penerbit Bumi Aksara.

Luthans, Fred. 2006. Perilaku Organisasi. Yogyakarta: Penerbit Andi.

Mathis, Rober L. dan John H. Jackson. 2006. Manajemen Sumber Daya Manusia. Jakarta: Penerbit Salemba Empat.

Mondy, R. Wayne. 2008. Manajemen Sumber Daya Manusia Jilid I Edisi 10. Jakarta: Penerbit Erlangga.

Nugroho, Triyono, 2009, http://triyononugroho.blogspot.com/Pengar uh Kompensasi dan Kepemimpinan Terhadap Kinerja Karyawan dengan Motivasi Sebagai Variabel Intervening: tahun akses 2013.

Panggabean, Sibarani. 2004. Manajemen Sumber Daya Manusia. Bogor: Penerbit Ghalia Indonesia.

Robbins, Stephen P. dan Timothy A. Judge. 2008. Perilaku Organisasi Edisi 12 Buku 2. Jakarta: Penerbit Salemba Empat.

Setiawan, 2011 , http://eprints.undip.ac.id/29450/1/Skripsi01 9.pdf: tahun akses 2013.

Simamora, Hendry. 2004. Manajemen Sumber Daya Manusia. Jakarta: Penerbit Erlangga.

Simbolon, Hotman. 2009. Statistika. Yogyakarta: Graha Ilmu.

Sopiah. 2008. Perilaku Organisasi. Yogyakarta: Penerbit Andi.

Sudewa,

Wira,

2012 , http://www.slideshare.net/wirasudewa90/co ntoh-proposalskripsi: tahun akses 2013.

Sugiyono. 2008. Metode Penelitian Kuantitatif Kualitatif dan R\&D. Bandung: Penerbit Alfabeta.

Wibowo. 2007. Manajemen Kinerja. Jakarta: Rajawali Pers. 